\title{
Mentorship comes from many sources
}

\author{
Shubha Tole obtained her BSc in Life Sciences and Biochemistry from St. Xavier's College, Mumbai, India, in 1987. \\ After a PhD from the California Institute of Technology in 1994, she did her postdoc at the University of Chicago. \\ In 1999, she joined the Tata Institute of Fundamental Research, in Mumbai, as a faculty member.
}

\section{Shubha Tole}

M y mother always hoped that I would be a doctor, a dream she had aspired to herself but could not pursue due to various circumstances. As an occupational therapist at Tata Memorial Hospital, Mumbai, she worked with underprivileged kids from rural India in the leukaemia ward. I helped her make costumes for their birthdays, and saw how it lit up their faces. It seemed natural that I would study medicine. My first turning point came in grade twelve, when Sam Waugh taught us gastrulation. This fantastic transformation of a ball of cells into an animal did not seem very connected with medicine, and I began wondering if there was more to biology. The 'multipotent' student in me differentiated down a neurocommitted pathway in May 1984, thanks to the Life Sciences exhibition at St. Xavier's College, Mumbai. This whetted my appetite for questions such as how sensory perception works, what is life, and whether consciousness is its ultimate manifestation.

Studying at St. Xavier's nurtured these interests, and my parents supported my applying to neuroscience programs in the United States. I joined the California Institute of Technology (Caltech), filled with excitement and trepidation. My journey into research began with a rude culture shock; in the male-dominated lab I joined was a poster of a naked man wearing only a condom - captioned 'dress for the occasion' - and another showing a dozen exposed male genitalia. It was before the era of gender sensitivity and, as a 21-year-old foreign student, I did not know if my feeling of alienation was valid. Work-wise, I had a rough start. Paul Patterson (a wonderful, if quirky and hands-off advisor) asked me (an inexperienced student) to set up the complicated Bonhoeffer retino-tectal assay. No one around knew how to dissect chick retinae or tecta, so I taught myself using an atlas and struggled to get things to work. This sink-or-swim experience, and the independence it required, marked a second turning point. I developed a thesis project in forebrain patterning, a field outside Paul's expertise that fascinated me when I examined the labelling pattern of monoclonal antibody FORSE-1 (Forebrain-surfaceembryonic-1) that I had helped generate. A

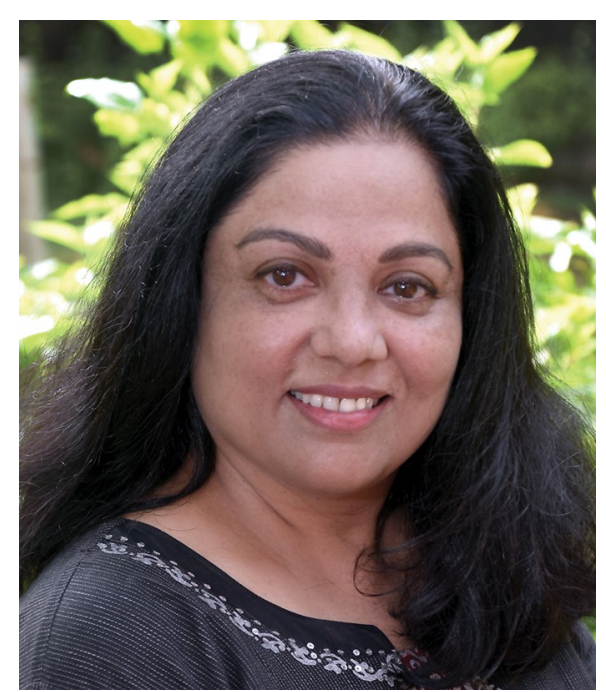

Credit: Jatin R. Acharya - TIFR

new postdoc in the lab, Karen Allendoerfer, started characterizing the FORSE-1 antigen. Karen and I would discuss our struggles, hopes and dreams, and I realized that each lab has a different dynamic that is strongly impacted by its gender balance and diversity; Karen and I called ourselves 'Feminists in FORSE. This treasured friendship and peer-mentorship continued after I left the lab; Karen and I would do journal clubs via telephone to discuss interesting papers.

My postdoc with Liz Grove, at the University of Chicago, started with many setbacks. My first six funding proposals were rejected, my first paper took three years and, with several incomplete stories, time was ticking. I was scrambling to keep up with my husband, whom I met in graduate school, and who was ready for a job search. My scientific interactions with Peggy Mason, a faculty member in my department, and with fellow postdocs, were invaluable. A key moment was when the American Association of University Women awarded me a fellowship for candidates intending to return and help women in their home countries. My husband and I dreamed of giving back to the society that had invested in our education. I wanted to provide research opportunities to Indian students restricted by finances or societal norms from traveling abroad for higher studies, in a way realizing my mum's dreams. Encouraged by this award, I applied for the Wellcome Trust Senior International fellowship to start my own lab at the Tata Institute of Fundamental Research (TIFR) in Mumbai. Mahendra Rao, a former student of Paul's and familiar with TIFR, gave valuable input for my application. Paul's excellent training in structuring presentations helped me in the job talk and the Wellcome Trust interview. This fellowship award was another turning point; it emboldened me to pursue risky projects, one of which led us to discover the hippocampal 'organizer' (Science 319, 304-309; 2008).

I am now established in the Indian scientific community, an active member in the Society for Neuroscience and International Brain Research Organization committees, an invited speaker at international meetings and a mentor to trainees whose careers I actively support. I have written about being a scientist and mother, about mentorship (https:// go.nature.com/2JUI2de) and how Indian societal norms constrain women in STEM fields (https://go.nature.com/2LKNHo4). I have pushed funding agencies to support pregnant postdocs by providing technical support during their year of maternity leave. I raised awareness about sexual harassment in Indian science (Curr. Sci. 114, 2425-2427; 2018). In my lab, posters show a snail's shell demonstrating the dextral/sinistral developmental decision; the 'HOLLYWOOD' sign pranked by gutsy undergrads to read 'CALTECH', and a 1913 quote by Rebecca West saved from an old Caltech newsletter, "I only know that I am called a feminist whenever I express sentiments that differentiate me from a doormat".

Shubha Tole

Department of Biological Sciences, Tata Institute of Fundamental Research,

Mumbai, India.

e-mail: stole@tifr.res.in

Twitter: @shubhatole

Published online: 28 August 2018

https://doi.org/10.1038/s41556-018-0189-x

Competing interests

The author declares no competing interests. 